\title{
In retrospect chosen by Owen Gingerich
}

\section{De revolutionibus orbium celestium ("On the revolutions of the heavenly spheres")}

by Nicolaus Copernicus (1543)

"You may have heard about the thesis of this book and are afraid that all the liberal arts are about to be thrown into confusion," proclaims the introduction to this book. "But these hypotheses need not be true nor even probable.... Perhaps philosophers will seek after truth, but an astronomer will just take what is simplest and neither will find truth unless it has been divinely revealed to him. If you expect to find truth here, beware, lest you leave a greater fool than when you entered."

For most sixteenth-century readers of De revolutionibus these were the words of one Nicolaus Copernicus of Torun, canon of the cathedral in the northernmost diocese of Poland, and an astronomer to be reckoned with. Only a few discerned otherwise, and only later was the introduction's anonymous author identified as the Lutheran clergyman Andreas Osiander. While acting as proofreader, Osiander helped the printer to add this protective boilerplate.

Misleading as it was in representing the views of Copernicus, it did save the book from condemnation for 73 years. Then, in 1616, Galileo's publicity precipitated action by the Roman Inquisition, which put $D e$ revolutionibus on the Index of Prohibited Books "until corrected". The ten corrections, announced in 1620 , were primarily to enhance the hypothetical stance advocated by Osiander.

Judging by the writing in the margins of extant copies, many readers managed to get only about $6 \%$ of the way into this formidably technical volume - this being the part that introduced the new heliocentric cosmology, which argued that "Only in this arrangement do we find a sure commensurability between the size of the orbit and its period".

A specialist minority skipped over the opening section and delved deeply into the remaining $94 \%$, filled with the geometry to

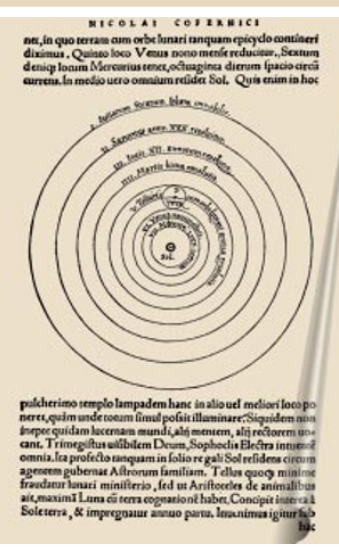

solve solar, lunar and planetary motion. There they found that Copernicus, driven by the aesthetic nature of uniform speed on perfect circles, had used a series of epicyclets to accomplish his goal. It is hard for us to imagine anyone getting steamed up by this sort of thing, and we can nod sympathetically with Arthur Koestler's declaration that this was the book nobody read. In fact, Koestler was quite wrong. There were surprisingly many readers, though rather few gave the technical passages intense scrutiny.

Despite the impression given

by innumerable secondary accounts, Copernicus had no observational proof of his heliocentric arrangement. It was an achievement in the mind's eye, a theory "pleasing to the mind". But it accorded in a reasoned way with many natural phenomena, which in the Sun-centred plan were "linked together as by golden chain", in the words of his young disciple, Georg Joachim Rheticus. As Copernicus pointed out, his scheme explained quite naturally why the retrograde motion of nearby Mars was larger than than that of more distant Jupiter, and why the still more distant stars themselves failed to show this annual backward wobble. "So vast, without any question, is the divine handiwork of the most excellent Creator." This was one of the passages censored by the Roman Inquisition. A pious statement, they thought, it exuded too great a whiff of reality, as if that is how God actually made the cosmos.

But did Copernicus actually believe in the physical reality of his system? Most probably yes. But elements of the later, technical parts of De revolutionibus leave a lingering doubt. For example, on the planetary latitudes Copernicus uses mechanisms entirely different from those he has earlier presented for the longitude. But surely a physically real system would demand the same mechanism for both latitudes and longitudes, and this is what the thorough-going realist Kepler eventually demanded, and which forced Copernicus onto the path that led to the elliptical orbit and the law of areas. Nevertheless, the vision of Copernicus formed the blueprint on which newtonian mechanics and the modern world would eventually be built.

Early on, De revolutionibus had a steady, if small, stream of readers.
The work then languished, made more or less obsolete by Kepler's Epitome of Copernican Astronomy. In 1939 an English edition, not altogether reliable, finally appeared. In 1976, Alistair Duncan's translation came out, followed by Edward Rosen's version in 1978. Rosen's is the more literate, especially in the early cosmological sections, whereas Duncan seems more reliable in the lengthier, technical parts. As an aid to understanding those technical parts, The Mathematical Astronomy of Copernicus's De Revolutionibus by Noel Swerdlow and Otto Neugebauer is unsurpassed.

Today the 1543 editio princeps of De revolutionibus orbium celestium has become an icon of scientific progress, the first great work of the astronomical revolution. As such, copies now fetch an astronomical price, up to US $\$ 300,000$. It is wonderful that achievements of the intellect, theories "pleasing to the mind", are now so highly regarded.

Owen Gingerich is at the HarvardSmithsonian Center for Astrophysics, 60 Garden St, Cambridge, Massachusetts 02138, USA. 